\title{
Erratum to: Plant abiotic stress-related RCI2/PMP3s: multigenes for multiple roles
}

\author{
Pedro S. C. F. Rocha ${ }^{1}$
}

Published online: 13 May 2016

(c) Springer-Verlag Berlin Heidelberg 2016

\section{Erratum to: Planta (2016) 243:1-12 \\ DOI 10.1007/s00425-015-2386-1}

The original version of this article unfortunately contained a mistake. The affiliation of the Pedro Rocha is incorrect. The correct affiliation is given below:

Key Laboratory of Agro-ecological Processes in Subtropical Region, Institute of Subtropical Agriculture, Chinese Academy of Sciences, Yuan Da Er Lu, 644, Changsha 410125, People's Republic of China.

The online version of the original article can be found under doi:10.1007/s00425-015-2386-1.

Pedro S. C. F. Rocha

procha@isa.ac.cn

1 Key Laboratory of Agro-ecological Processes in Subtropical

Region, Institute of Subtropical Agriculture, Chinese

Academy of Sciences, Yuan Da Er Lu, 644,

Changsha 410125, People's Republic of China 